\title{
Principles of "Constructivism" in Foreign Language Teaching
}

\author{
Muna Aljohani \\ University of Tabuk, Tabuk, Saudi Arabia
}

\begin{abstract}
The core ideas of Constructivism were mentioned by John Dewey, so it is not a new idea. Constructivism claims that each learner constructs knowledge individually and socially. The "glue" that holds the constructs together is meaning. Knowledge is not "out there", as the realist philosophers such as Plato claimed. Knowledge is always an interpretation of reality, not a "true" representation of it. Thus, the aims of this study are: (1) to shed the light on the schools of constructivism, and (2) to clarify the principles of the constructivist learning in general and in language teaching in particular.
\end{abstract}

Keywords: constructivism, language learning/teaching, principles

\section{Introduction}

Constructivism has emerged in recent years as a dominant paradigm in education and has had a major intellectual impact on the development of pedagogy, rooted in the cognitive developmental of Piaget and in the sociocultural theory of Vygotsky, constructivist notions have had an impact on the development and application of technologically enhanced micro worlds and on linguistic investigation into literacy and narrative development constructivist learning has developed as a substantial approach to teaching.

During past decades many researchers and scientist had elaborated on the historical precedents for constructivist learning theory. In this view constructivism represents the shift from education based on behaviorism, to education based on cognitive theory. Moreover, the current emphasis on standards based accreditation and reconceptualization of teacher education programs will likely expand the horizons of language pedagogy, bringing constructivist approaches to the foreground in language teacher education and opening new avenues for linguistic and interdisciplinary classroom-based research. Constructivism has hitherto not played a visible role in language pedagogy and teacher education, although notions that are central to constructivism have been integrated into language education through other pedagogical models. In recent years, language pedagogy has integrated a rich palette of instructional approaches that underscore the centrality and diversity of learners and their active engagement in authentic and meaningful pursuits as individuals and within communities of learners (Kaufman, 2004). Thus, the aims of this study are:

(1) to shed the light on the schools of constructivism

(2) to clarify the principles of the constructivist learning in general and in language teaching in particular.

\section{Method}

The researcher will use the descriptive method.

Muna Aljohani, Ph.D., Assistant Professor, University of Tabuk. 


\section{Theoretical Frame Work: Constructivist Theories of Learning}

The basic premise of constructivist theories is that people create their own meaning through experience. Constructivism has its roots in the cognitive theories of Piaget and Vygotsky and embraces several aspects of both of those theories. From Piaget we get active learning, schemes, assimilation and accommodation, etc. From Vygotsky we get social constructivism, group work, apprenticeship, etc. Constructivism embraces a "top-down" rather than a "bottom-up" instructional methodology. This means that, rather than teach all of the details that lead to a main idea, students discover the main idea and then derive the detail.

In conclusion, Gul (2016) stated that:

Scholars and philosophers such as Dewey (1916), Piaget (1973), and Vygotsky (1978) had different perspectives and ideas on constructivism although they were arguing mainly around the same epistemology and ontology. In other words, the scholars interpreted the same concept from their different angles, experiences, minds, and worlds...). In other words, constructivism is in the mind of knowers where they construct a reality, orinterpret it, relying on their experiences, and how they deal with how they are constructed (Brooks \& Brooks, 1999; Jonassen, 1992). Experience is also important in constructivism. In that regard, knowledge is the life itself and it is the learners' experiences, not something abstract out there independent from the learner (Dewey, 1916, 1938/1997). Therefore, teaching and learning processes should be related to the real practical world. Further, even the classrooms are designed and formed in a way where not only the teacher talks, but the students ask critical questions, share ideas and experiences, and exchange knowledge interactively (Brooks \& Brooks, 1999).

\section{Main Contributors to Constructivism}

Constructivism: the main principles in constructivism are: Knowledge is Constructed; the Learner is an Active Creator. Piaget (1896-1980) can be considered the father of the theory of constructivism. Constructivism suggests that the learner needs to be proactive in how they learn, taking new information, and shaping it to their understanding, rather than just sitting still and passively absorbing information like a sponge. In recent decades, this method of learning has gradually become more popular in the school system.

Jerome Bruner (1915- ) established the Constructivism, where the interactionism approach to language development, exploring such themes as the acquisition of communicative intents and the development of their linguistic expression, the interactive context of language use in early childhood, and the role of parental input and scaffolding behavior in the acquisition of linguistic forms. This work rests on the assumptions of a social constructivist theory of meaning according to which meaningful participation in the social life of a group as well as meaningful use of language involves an interpersonal, intersubjective, collaborative process of creating shared meaning. The elucidation of this process became the focus of Bruner's next period of work.

Then David Ausubel (1918-2008) also considered one of the Subsumption of the Theory.

Chris Argyris (1923- ) introduced Double Loop Learning theory he used the learning process of double-loop learning. Chris Argyris' (1923- ) Double Loop Learning theory consists of the following: (1) impact of organization structures, control systems and management on individuals; (2) organizational changes involving top executives; (3) role of social scientist as both researcher and actor (action science); (4) individual and organizational learning (single and double-loop learning; espoused theory and theory-in action). This is the result of the collaborative research of Argyris and Schön. They postulated that human beings are idealistic and have a sense of right and wrong. They have a preconceived idea of the goodness they are capable of and this is what they called the espoused theory. Unknown to them, there is a "master program" which everyone has which seeks to (1) remain in unilateral control; (2) maximise "winning" and minimize "losing"; (3) suppress negative feelings; and (4) to be rational in their thinking (Argris, 2004). 
David Kolb Learning Styles: here, Kolb explains that different people naturally prefer a certain single different learning style. Various factors influence a person's preferred style: notably in his experiential learning theory model (ELT) Kolb defined three stages of a person's development. The development stages that Kolb identified are: (1) Acquisition — birth to adolescence — development of basic abilities and "cognitive structures"; (2) Specialization - schooling, early work and personal experiences of adulthood - the development of a particular "specialized learning style" shaped by "social, educational, and organizational socialization"; (3) Integration - mid-career through to later life — expression of non-dominant learning style in work and personal life (Tang, 2016).

John Flavell Metacognition (1971-1987): in (1971) Flavell used the term metamemory in regard to an individual's ability to manage and monitor the input, storage, search and retrieval of the contents of his own memory. Flavell (1987) also offered clarification on the term metacognitive experience. He defined metacognitive experience as affective or cognitive awareness that is relevant to one's thinking processes. He described a variety of examples such as feeling that one is not understanding something, feeling that something is difficult or easy to remember, solve, or comprehend, and feeling that one is approaching or failing to approach a cognitive goal. Metacognitive experiences arise when they are explicitly demanded by a situation. Flavell (1987) also proposed that the emergence in the child of awareness of the flow of time, and specifically awareness of future time could support the ability to form metacognitive goals. Another change that occurs during childhood development is the sense of the self as an active agent in one's own experiences. As early as 1987 Flavell was actively encouraging the development of metacognition in school children; in schools there are abundant opportunities to develop metacognitive knowledge about persons, tasks, and strategies (Cooper, 2016).

Roger Schank's Script Theories (1970): by his research Schank's theories address the structure of knowledge, with particular interest on language understanding and higher thinking skills. His early work in the 1970 's led to the development of contextual dependency theory, which attempted to explain how meaning is derived from sentences. He introduced the concept of scripts, plans, and themes in 1977; this level of theory dealt with understanding at the story level. His work in the 1980's continued to develop the theory to encompass other levels and aspects of cognition. Schank was a proponent of the notion that all memory is episodic, meaning it is organized around personal experience rather than semantic (meaning) categories for more information of these authors and their theories. ${ }^{1}$

\section{Methods Used in Constructivism Theory}

In constructivism, students are encouraged to learn main ideas on their own through discovery learning. Examples include learning about compound words by playing with word strips, learning about addition and subtraction through the use of manipulatives, or learning about capacity through experimentation with different sizes of objects.

Personal theories, or students' own ideas about how things work, play a large role in constructivism as we attempt to provide activities that clarify and correct misconceptions. Additional constructivist strategies include presenting others' viewpoints, promoting dialogue, and emphasizing conceptual understanding rather than rote learning.

${ }^{1}$ See Cooper, S. (2016) from http://www.lifecircles-inc.com. 
- From Piaget we get active learning, schemes, assimilation and accommodation, etc.

- From Vygotsky we get social constructivism, group work, apprenticeship, etc.

Constructivism embraces a "top-down" rather than a "bottom-up" instructional methodology. This means that, rather than teach all of the details that lead to a main idea, students discover the main idea and then derive the details.

- A major theme in the theoretical framework of Bruner is that learning is an active process in which learners construct new ideas or concepts based upon their current and past knowledge.

- The learner selects and transforms information, constructs hypotheses, and makes decisions, relying on a cognitive structure to do so.

- Cognitive structure (i.e., schema, mental models) provides meaning and organization to experiences and allows the individual to "go beyond the information given".

\section{Assumptions}

Bruner (1966) states that a theory of instruction should address four major aspects:

(1) predisposition towards learning;

(2) the ways in which a body of knowledge can be structured so that it can be most readily grasped by the learner;

(3) the most effective sequences in which to present material;

(4) Good methods for structuring knowledge should result in simplifying, generating new propositions, and increasing the manipulation of information.

\section{Practice}

- The instructor should encourage students to discover principles by themselves.

- The instructor and student should engage in an active dialog (i.e., Socratic learning, inquiry approach).

- Curriculum should be organized in a spiral manner so that the student continually builds upon what s/he has already learned.

- The task of the instructor is to translate information to be learned into a format appropriate to the learner's current state of understanding. (e.g. graphic organizers)

- Parallel: Ausubel's Sub sumption Theory shares many of the same ideas, such as the organizational strength of cognitive structures. Thus, he recommends the use of advanced organizers to prepare students to receive what they will be given by instructors.

The major difference is that he sees subsumption as the reorganization of existing cognitive structures rather than the development of new cognitive structures, as suggested by the constructivists.

\section{Main Principles ${ }^{2}$}

1. Instruction must be concerned with the experiences and contexts that make the student willing and able to learn (readiness).

2. Instruction must be structured so that it can be easily grasped by the student (spiral organization).

3. Instruction should be designed to facilitate extrapolation and or fill in the gaps (going beyond the information given) by stimulating cognitive skills required for application.

2 See from http://www.west.net/ ger/Orientation/constructivist.html. 


\section{Schools of Constructivism: In the Following Figure Is Clarification of Schools' Constructivism}

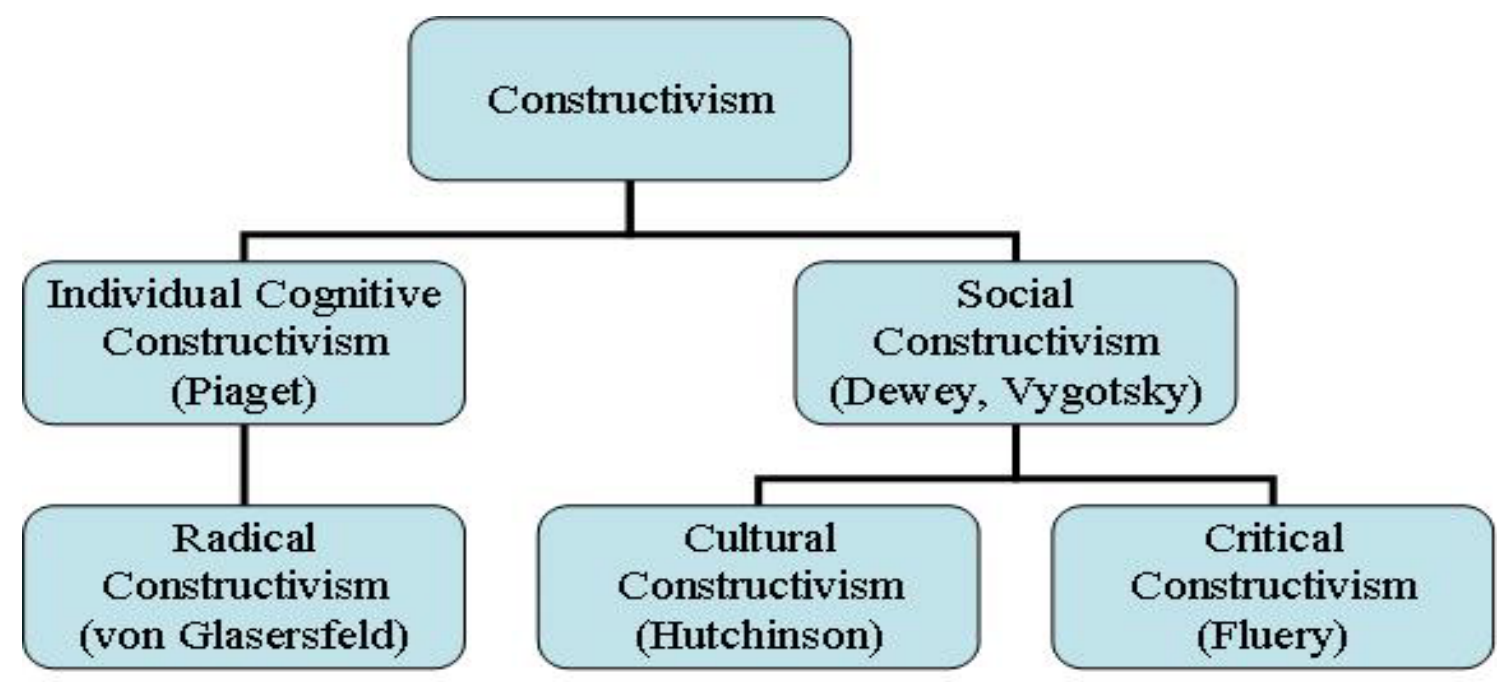

Figure 1. Schools of constructivism. ${ }^{3}$

Trivial (Cognitive) constructivism. The concept that knowledge is actively constructed by the learner, not passively received by the environment. It is derived from the assimilation-accommodation and schema models of Piaget.

Radical constructivism. It is derived from Von Glaserfeld (1990). Von Glaserfeld put forth the notion that the learner's constructions do not necessarily reflect knowledge of a "real world". Coming to know is a process of dynamic adaptation toward viable interpretations of experiences. We have no way of knowing what "real" reality might be, since input is filtered. Previous constructs also influence our perceptions of current experience. We construct "viable" models of what reality is based on social and physical constraints.

Social constructivism. This was the theory of Vygotsky in the late 1970's. Vygotsky's point of view was that acquisition and participation were synergistic strategies in learning situations. Aspects of participation involved teaching in contexts that could be meaningful to students based on their personal and social history, negotiating, class discussions, small group collaborative learning with projects and tasks, and valuing meaningful activity over correct answers. Social constructivism emphasizes that learning takes place through interactions with other students, teachers, and the world-at-large (Vygotsky, 1978).

Cultural constructivism. It brings in a wider context to learning, including customs, religion, language, physiology, tools available (computers, books, etc.). Tools are used to redistribute the cognitive load between the learner and the tool, and can affect the mind beyond actual use by changing one's skills, perspectives, and responses.

Critical constructivism. Critical constructivism adds a dimension of critical evaluation and cultural reform to the educational process. This approach incorporates the use of Communicative Ethics which defines the conditions for establishing dialog oriented toward mutual understanding among learners and teachers. Communicative Ethics promotes (1) primary concern for maintaining empathetic, caring, and trusting relationships, (2) commitment to achieve reciprocal understanding of goals, interests and standards, and (3) concern for and critical awareness of the often-invisible rules of the classroom, including social and cultural myths.

${ }^{3}$ Figure 2: schools are adopted from https://jean-piaget.wikispaces.com/Constructivism. 
Prevalent myths in today's educational system include (1) cold reason, the notion of knowledge as eternal truth, teacher as transmitter of objective truths, and curriculum as a product which is delivered, and (2) hard control, the perspective of teacher as controller, in which there is a power differential between teacher and learners, and a dominance-subordinate relationship.

The behavioral approach suggests that in absence of knowing the internal processes of the learner, the focus is on the external - the behavior of the learner. The behaviorist learning model follows the pattern, $\mathrm{A} \rightarrow$ $\mathrm{B} \rightarrow \mathrm{C}$, where the environment presents the antecedent $(\mathrm{A})$, that prompts a behavior (B), that is followed by a consequence (C). Characteristics of this approach include passivity of the learner, rote learning and methods of reinforcement.

The cognitive orientation goes beyond the external environment, and focuses on the internal where learning is a process managed within the learner's long and short-term memory. The instructor controls and directs learning through planned instruction, selection of content, and teaches the learner through the building of knowledge (or skills) using a hierarchical approach going from the simple to complex (Roblyer \& Doering, 2010).

\section{Constructivism and Learning}

The "revolution" which began with humanistic approach and was followed by cognitive theory was brought to a stage that is current nowadays - constructivism. According to constructivists, learners create their own individual representations of the world. As in humanistic approach, the learner is treated as one holistic unit, whose emotions and feelings are important because they shape learners' attitude. Similarly, their creativity allows them to construct the view on the world in their own unique way.

The cognitive processes are reflected in analyzing and operating on what is of utmost significance in constructivists' view - the things experienced by the learners through their interaction with the environment (there are, however, two main constructivist theories - cognitive constructivism and social constructivismwhich differ in regard to the role that the environment plays in the learners' cognitive development). Currently, constructivism is the most supported approach to language learning and its main contribution to educational psychology is the learner-centred approach, which emphasizes the autonomy of learners in the process of their education as the realist philosophers such as Plato claimed.

\section{Principles of Constructivist Learning}

1. The learner uses sensory input and does something with it, ultimately making meaning of it.

2. Learning consists of both constructing meaning and constructing systems of meaning. Learning is layered.

3. Learning occurs in the mind. Physical activity may be necessary, but is not sufficient alone.

4. Learning involves language. Vygotsky believed that language and learning are inextricably intermeshed.

5. Learning is a social activity.

6. Learning is contextual. We do not isolate facts from the situations and environments in which they are relevant.

7. Knowledge is necessary for learning. It is the basis of structure and meaning-making. The more we know, the more we can learn. 
8. Learning takes time; it is not spontaneous. Learners go over information, ponder them, use them, practice, experiment.

9. Motivation is a necessary component, because it causes the learner's sensory apparatus to be activated.

Relevance, curiosity, fun, accomplishment, achievement, external rewards and other motivators facilitate ease of learning.

Our current higher education system is grounded in behaviorist and cognitive theories.

\section{Constructivism and Language Teaching}

The foundation of a constructivist approach as:

1. about constructing knowledge, not receiving it

2. about thinking and analyzing, not accumulating memorizing

3. about understanding and applying, not repeating back

4. being active, not passive. (Marlowe \& Page, 2005)

Constructivist learning has developed as a substantial approach to teaching. During past decades many researchers and scientists had elaborated on the historical precedents for constructivist learning theory. In this view constructivism represents the shift from education based on behaviorism, to education based on cognitive theory.

Thus, behaviorist epistemology essence is based on intelligence, domains of objectives, levels of knowledge and reinforcement, however in the case of constructivist epistemology it is the learners who construct their knowledge on the basis of interaction with the environment.

The primary message of constructivism is that active learning enables the students to construct their own knowledge and make their own meaning of what is being thought.

\section{The Principle of “Constructivist” Foreign Language Teaching (FLT)}

In two recent articles $(1994,1997)$, Dieter Wolff, a prominent German FLT researcher, outlined the features of foreign language teaching on constructivist lines.

The first essay, Wolff places "constructivist" FLT in opposition to the traditional forms of "instructivism" in language teaching (see Figure 2). Most probably, Wolff borrowed the binarism "constructivism vs. instructivism" from American colleagues who had drawn it from the discussion concerning science education theory, where this term has quite frequently been used since the 1980's.

In concordance with these disciplines, Wolff defines instructivism as directed by a paedagogical-psychological concept, according to which learners are considered as "reactive beings" ("reactive Wesen") either accepting or not accepting the material offered by the teacher. According to Wolff (1997, p. 47; as cited in Reinfried, 2000), constructivists, however, postulate that, learning is a process which is highly subjective, autonomous, and active. 


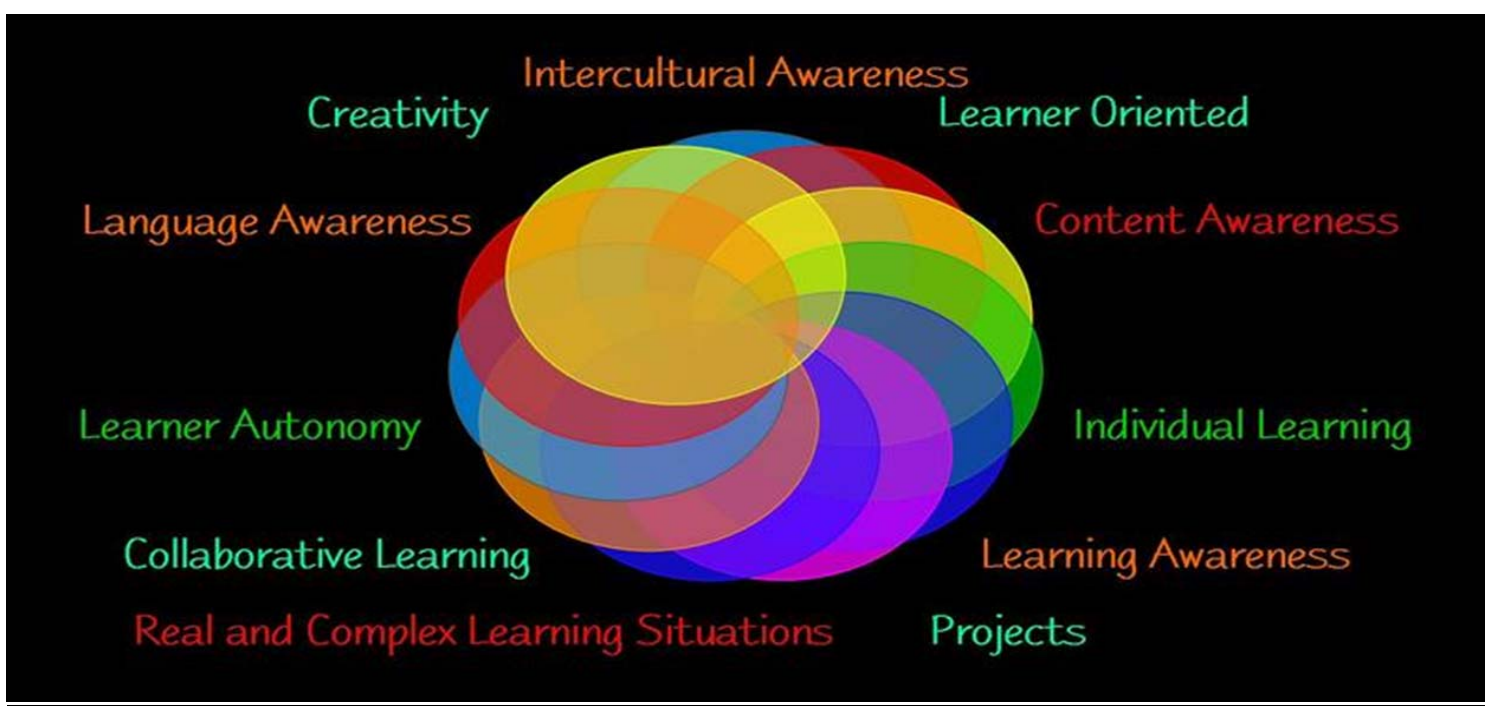

Figure 2. Principles of constructivist foreign language teaching.

\section{Principles of "Constructivist" FLT}

1. It is based on action-orientedness and cooperative learning, creative forms of classroom work, learning by projects, and, LBT - learning by teaching are essential in the constructivism classroom

2. More concentration on the Learner-centredness which means more individualisation of learning, and autonomy of learner

3. Process-related awareness is essential in the constructivist classroom and learning awareness, language awareness, intercultural awareness

4. Holistic language experience is the soul of this theory in the language classes, which depends on content-orientedness, authentic and complex learning environment

One of the most important principles in constructivist approach to language teaching is action orientedness. Cooperative learning (such as pair work, group work or any other social forms of learning), creative and active participation in classroom activities, learning by preparing various projects as well as learning by teaching (when the student is asked to take over teacher's role) have been treated as the major tasks referring to the action oriented method.

The second substantial principle in constructivism FLT is individualisation of learning which is centred on the learner. Dieter Wolff, a notable German FLT researcher claims that learning can only be influenced by teaching in a very restricted way.

It is the learner who is allowed to decide about the fragments and sections of the materials provided by the teacher during the lesson. This possibility to make choices fosters learner's autonomy, thus it takes into account their preferable style and type of learning. However, the crucial thing is that beforehand the learner should be instructed on how to become aware and take responsibility of his/her own learning, what considers strategies and techniques selected and applied during learning. What is also important is that learning awareness should be complemented by language awareness as well as intercultural awareness.

Another principle of constructivism refers to holistic language experience which refers to content-oriented FLT and usually takes place in bilingual classes or project instruction. According to this approach, acquiring foreign language will be effective in authentic and complex learning environment or situation. Reinfried (2000) 
comes to the conclusion that radical constructivism will not work as a methodological meta-theory for language learning because it has a number of serious weaknesses at the explanatory level as well as areas of inconsistency. He argues, for a realistic constructivist version of the theory, which may well serve as an epistemological basis and which, at the same time, opposes learner-centred theories taking an absolutist position in language learning. Moreover, Gul (2016) reviewed several studies and show that constructivist ways of teaching English is better when compared to the traditional approach. For instance, he mentioned that Al Muhaimeed (2013) found that using a constructivist technique helped students in schools in Saudi Arabia increase reading comprehension more than that of the traditional teaching method of the English language. In addition, that constructivist practice was a better way for English language teaching when compared to the traditional teaching method of the English language, and stated that Nikitina (2010) also found noticeable evidence that when the students were allowed to do constructivist activities such as using visuals and preparing a video project with teamwork, they learned a foreign language better. She indicated that the students liked the activity and considered it as beneficial. Moreover, he added that in another study conducted in a public school in India, Sengupta (2015) showed that by engaging the students with the collaborative writing task they made noticeable progress. The researcher concluded that the project "helped generate the learners' original ideas and provided an opportunity to generate content through engagement with the computer and artwork".

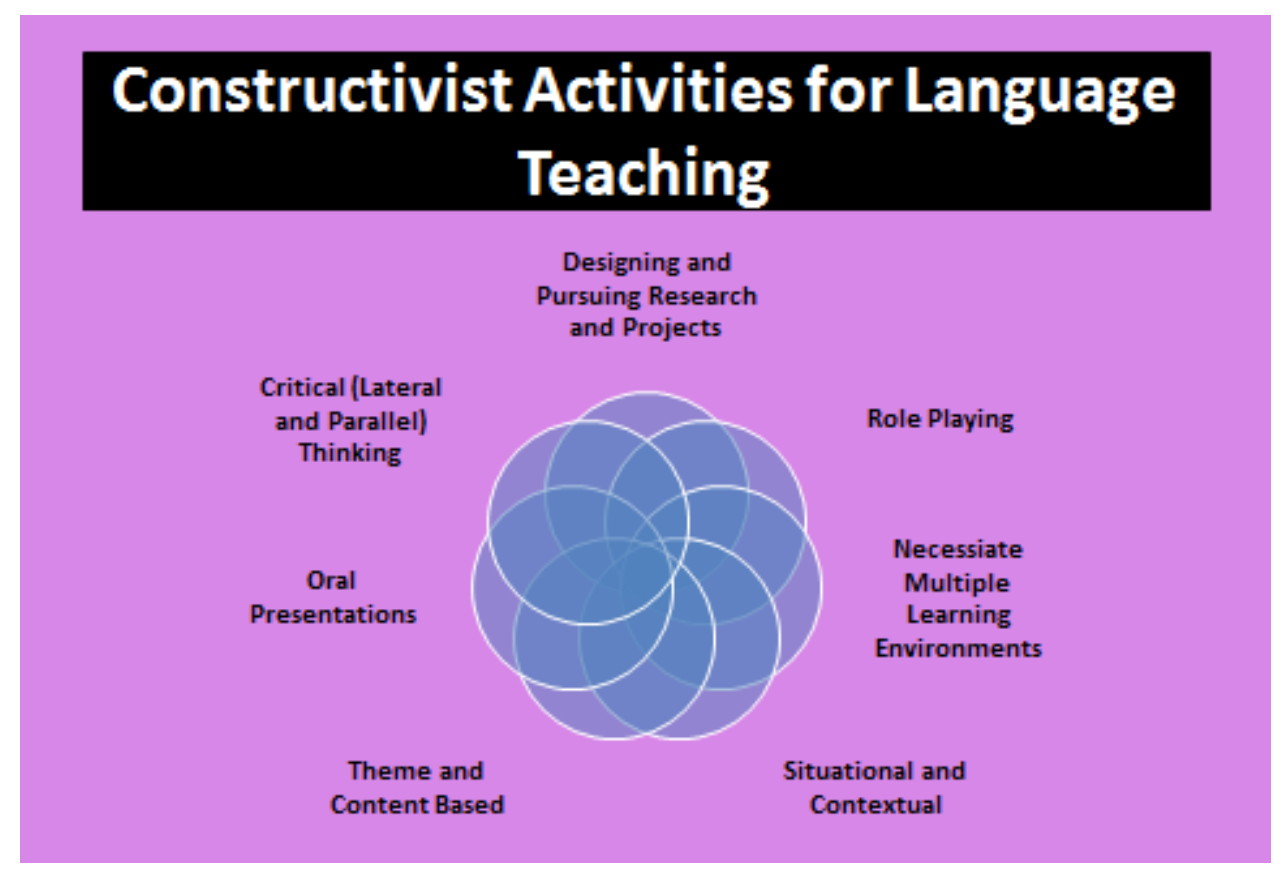

Figure 3. Constructivist activities for language teaching.

Students can construct additional knowledge by writing: poems, short plays, screenplays, legal briefs, song lyrics, journals, diaries, memoirs, travelogues, interviews, letters (or e-mail) to experts, original advertisements, new endings for stories or songs, and "what if..." thought experiments.

Students can construct additional knowledge by taking/inventing/designing/drawing: posters, cartoons, timelines, models, charts, maps, graphs, board games, concept maps, and multimedia presentations

Students can construct additional knowledge by performing/presenting, a play, a concert, role-play, lecture (such as a well-known person from history) and collected songs about a topic from another era. 


\section{Nine Characteristics of a Constructivist Teacher}

(1) Teacher serves as one of many resources for students, not necessarily the primary source of information.

(2) The teacher engages students in experiences that challenge previous conceptions of their existing knowledge.

(3) The teacher uses student responses in the planning of next lessons and seeks elaboration of students' initial responses.

(4) The teacher encourages questions and discussion among students by asking open-ended questions.

(5) The teacher assists students to understand their own cognitive processes (metacognition) by using cognitive terminology such as classify, analyze, create, organize, hierarchy, etc. when framing tasks.

(6) The teacher encourages and accepts student autonomy and initiative by being willing to let go of classroom control.

(7) The teacher makes available raw data and primary resources, along with manipulative and interactive physical materials.

(8) The teacher does not separate knowing from the process of finding out nouns and verbs.

(9) The teacher facilitates clear communication from students in writing and verbal responses, from the point of view that communication comes from ones deep structural understanding of the concepts being communicated. When they can communicate clearly and meaningfully, they have truly integrated the new learning.

\section{Conclusion and Recommendations}

Like other instructional theories, as Tam (2000) stated, constructivism cannot be the panacea for all instructional problems. It has its own limitations and problems for learning situations that may mitigate against its application.

Constructivism holds important lessons for how to interpret the results of learning and for how to design environments to support learning. According to the constructivist views of learning, as individuals bring different background knowledge, experience, and interests to the learning situation, they make unique connections in building their knowledge.

Students and teachers both play a role in facilitating and generating knowledge. Students are encouraged to question each other's understanding and explain their own perspectives. These opportunities help hand over responsibility for knowledge generation to the learners (Maxwell, 1995, as cited in Tam, 2000).

One of the most important principles in constructivist approach to language teaching is action orientedness. Cooperative learning (such as pair work, group work or any other social forms of learning), learner-centred theories take an absolutist position in language learning.

Instruction must be concerned with the experiences and contexts that make the student willing and able to learn (readiness).

Aspects of participation involved teaching in contexts that could be meaningful to students based on their personal and social history, negotiating, class discussions, small group collaborative learning with projects and tasks, and valuing meaningful activity over correct answers. Social constructivism emphasizes that learning takes place through interactions with other students, teachers, and the world at large. 


\section{References}

Argris, C. (2004). Teaching smart people how to learn. In Harvard business review on developing leaders (pp. 83-110). Boston: Harvard Business School Publishing Corporation.

Cooper, S. (2016a). Metacognitive research. The theories of learning in educational psychology. Retrieved from http://www.lifecircles-inc.com/Learningtheories/learningmap.html

Cooper, S. (2016b). Metacognitive research. Roger Schank Script Theory. Retrieved from http://www.lifecircles-inc.com/

Cooper, S. (2016bc). Metacognitive research. John Flavell Theory. Retrieved from http://www.lifecircles-inc.com/

Gagnon, Jr. G. W., \& Collay, M. (2001). Designing for learning: Six elements in constructivist classrooms. Thousand Oaks, CA, USA: Corwin Press, Inc.

Gray, A. (1997). Constructivist teaching and learning. SSTA Research Centre Report. Retrieved from http://saskschoolboards.ca/research/instruction/97-07.htm

Gul, A. (2016). Constructivism as a new notion in English language education in Turkey (A dissertation submitted to the Kent State University College of Education, Health, and Human Services in partial fulfillment of the requirements for the degree of Doctor of Philosophy, Kent University).

Kaufman, D. (2004). Constructivist issues in language learning and teaching. Annual Review of Applied Linguistics, 24, 303 B319.

Kearsley, G. (n.d.). Theory in practice database. George Washington University Online. Retrieved from http://gwis.circ.gwu.edu/ tip/bruner.html

Loman, M. (2002). Constructivist approach. Learning Theory. Retrieved from http://www.encyclopedia.com

Marlowe, B. A., \& Page, M. L. (2005). Creating and sustaining the constructivist classroom (2nd ed.). Thousand Oaks, CA: Corwin Press.

Reinfried, M. (2000). Can radical constructivism achieve a viable basis for foreign language teaching? - A refutation of the "Wolff-Wendt" theorem. Retrieved from http://webdoc.gwdg.de/edoc/ia/eese/artic20/marcus/8_2000.html

Roblyer, M. D., \& Doering, A. H. (2010). Integrating educational technology into teaching. UK: Pearson Publishing.

Tam, M. (2000). Constrcutivism, instructional design, and technology: Implications for transforming distance education. Educational Technology \& Society, 3(2).

Tang, A. (2016). Learning theories of Chris Argyris and Donald Schön. Retrieved from http://wm ww.kairos2.com

The theories of learning in educational psychology. Retrieved (2016) from http://www.lifecircles-inc.com/Learningtheories/learningmap.html

Williams, M., \& Burden, R. L. (1997). Psychology for language teaching: A social constructivist approach. Cambridge: Cambridge University Press. 